\title{
Bakterienes
}

\section{utrettelige beskytter}

\author{
15. februar 1967 signerte Tore Midtvedt en fredsavtale med mikrobene. Siden da har de vært \\ trofaste allierte og sammen kjempet seg stadig nærmere den medisinske kunnskapsfronten.
}

\begin{abstract}
- Den dagen publiserte jeg den viktigste artikkelen i hele mitt liv i Tidsskriftet.
\end{abstract} Tarmfloraens fysiologiske betydning het den. Det eneste jeg visste da jeg tok embetseksamen noen år tidligere var at tarmbakterier utgjør femti prosent av feces' masse og kan være av betydning for konsistensen. Man hadde ingen forståelse for dette da, forteller Tore Midtvedt.

Selv hadde han forstått at tarmbakteriene er av betydning for langt mer enn konsistensen på feces. Han fordypet seg etter hvert $\mathrm{i}$ epigenetikkens verden og kunne observere hvordan alle de små livene som leves inne i oss påvirker hvordan vi selv lever.

- Vennskapet med bakteriene erklærte jeg med den artikkelen, og gjennom hele resten av livet har jeg sett hva de betyr for oss. Husk på at der du sitter har du langt flere mikrobegener i deg enn du har egne gener. Du er bare en vandrende beholder for bakteriene og deres gener. Du er ikke noe annet, forklarer mikrobiologen med et skuldertrekk. Han sender meg et medfølende smil der jeg sitter med knust selvbilde på andre siden av bordet og smiler tomt tilbake.

Før jeg plasserte dem i den røde stolen, fraktet jeg selv mine bakterier og deres gener på T-banen fra Oslo sentrum ut mot Bærum. Så bar jeg dem trygt over et asfaltlandskap som en frisk dusj med underkjølt regn hadde gjort til terrengskøytebane. Til slutt ble vi sluppet inn av en blid, eldre herremann med sort pologenser, sort bukse og et rolig, ettertenksomt blikk innrammet av hvitt hår og skjegg. En bakteriebeholder av ypperste merke, produsert i 1934.

\section{Jakten på malignolipinet}

Opprinnelig hadde Tore Midtvedt helt andre planer enn å bli profesjonell bestevenn med bakteriene og vie livet til iherdig forskning på de forskjellige småtassene og deres egenskaper.

- Jeg hadde overhodet ikke tenkt å bli lege. Jeg hadde en drøm om å bli proffsyk- list og vinne Tour de France, jeg. Og kanskje kunne jeg gjort det også? Jeg tapte det første sykkelløpet jeg stilte opp i og vant resten. Men for all del - nivået i norsk sykling rundt 1950 var veldig lavt. Jeg hadde jo ikke gir på sykkelen engang, men det spilte ingen rolle.

- Hvorfor fortsatte du ikke med det?

- Vi kan gå til 18. juni 1952. Jeg hadde nettopp tatt artium i Kristiansand og min mor var innlagt på Radiumhospitalet for kreft. Vi var alle i Oslo, for vi visste at hun kom til å dø. Men han som senere ble min svoger kontaktet Gymnasierådet den dagen sensuren falt, fikk karakterene mine, og

\section{«Jeg starter ofte å jobbe i tretiden om natten, for da er det så få som ringer»}

ringte til sykehuset klokken 1300. Resultatene var gode, og da jeg gikk inn og fortalte min mor om det, så hun opp på meg og sa: «Tore, du må love å begynne å studere medisin.» Jeg sa bare «ja». En time senere døde hun.

Den pliktoppfyllende sønnen begynte studiet i Oslo, men ble sendt til Bergen for å fullføre løpet da medisinstudiet der skulle etableres. I siste termin fortalte farmakologiprofessor Karl Closs om et spesielt og mystisk stoff $\mathrm{i}$ alt kreftvev som ble kalt malignolipin. Midtvedt bet seg merke i dette og søkte seg senere til Kaptein W. Wilhelmsen og Frues Bakteriologiske Institutt på Rikshospitalet for å forske på kreftgåten.

- Mange av mine venner var på andre sykehus i Oslo-området og kunne sende meg kreftvev. Så jeg begynte å ekstrahere for å finne dette malignolipinet, men fant ingenting. Til slutt samlet jeg alt kreftvevet, jeg tror det var nærmere 20 kilo, og brukte all alkoholen som var på hele instituttet, men det var like tomt. Sånn var bakgrunnen for at jeg begynte i mikrobiologien: jeg skulle finne malignolipinet som jeg aldri fant.

\section{Midt i smørøyet}

I begynnelsen av 1960-årene sendte thalidomid-skandalen et kaldt gufs innover gangene på alle verdens sykehus og laboratorier. Gravide som hadde spist de kvalmestillende tablettene fra et legemiddelselskap i Vest-Tyskland fødte døde og misdannede barn. Det var en katastrofe. Men i kjølvannet fulgte også medisinske fremskritt.

Tore Midtvedt studerte selv det forhatte molekylet, synes det hadde likheter med vitamin $B_{2}$, riboflavin, og dro til Stockholm 1. april 1963 for å overbevise svenskene om å la ham forske på thalidomid i deres bakteriefrie dyr.

- Jeg hadde fått audiens hos professoren på Karolinska i en halvtime. Etter å ha forsøkt å motsi meg i to timer sa han: «Men dette prosjektet er jo som å ta dobbel saltomortale på slakk line!», så jeg svarte som Ibsen at «hvor utgangspunktet er galest, blir titt resultatet originalest!». Så tilbød han meg jobb, og jeg ble «visiting scientist» på Karolinska samme høst.

- Og der ble du senere professor i medisinsk mikrobiell økologi. Hva er det egentlig?

- Den avdelingen jeg var på het før navneskiftet Institusjon for medisinsk symbioseforskning. Så ble økologi etter hvert et hedersord, og jeg hadde nok den første professortittelen i verden på akkurat det. Jeg har i hvert fall ikke hørt om noen andre verken før eller etter. Men på Karolinska hadde man altså en kullsviertro på at ... - Man hadde hva?

- En kullsviertro. Det er et gammelt uttrykk. Men man var altså sikre på at tarmfloraen spilte en viktig fysiologisk rolle. Jeg disputerte på gallesyrer og visste en del om 


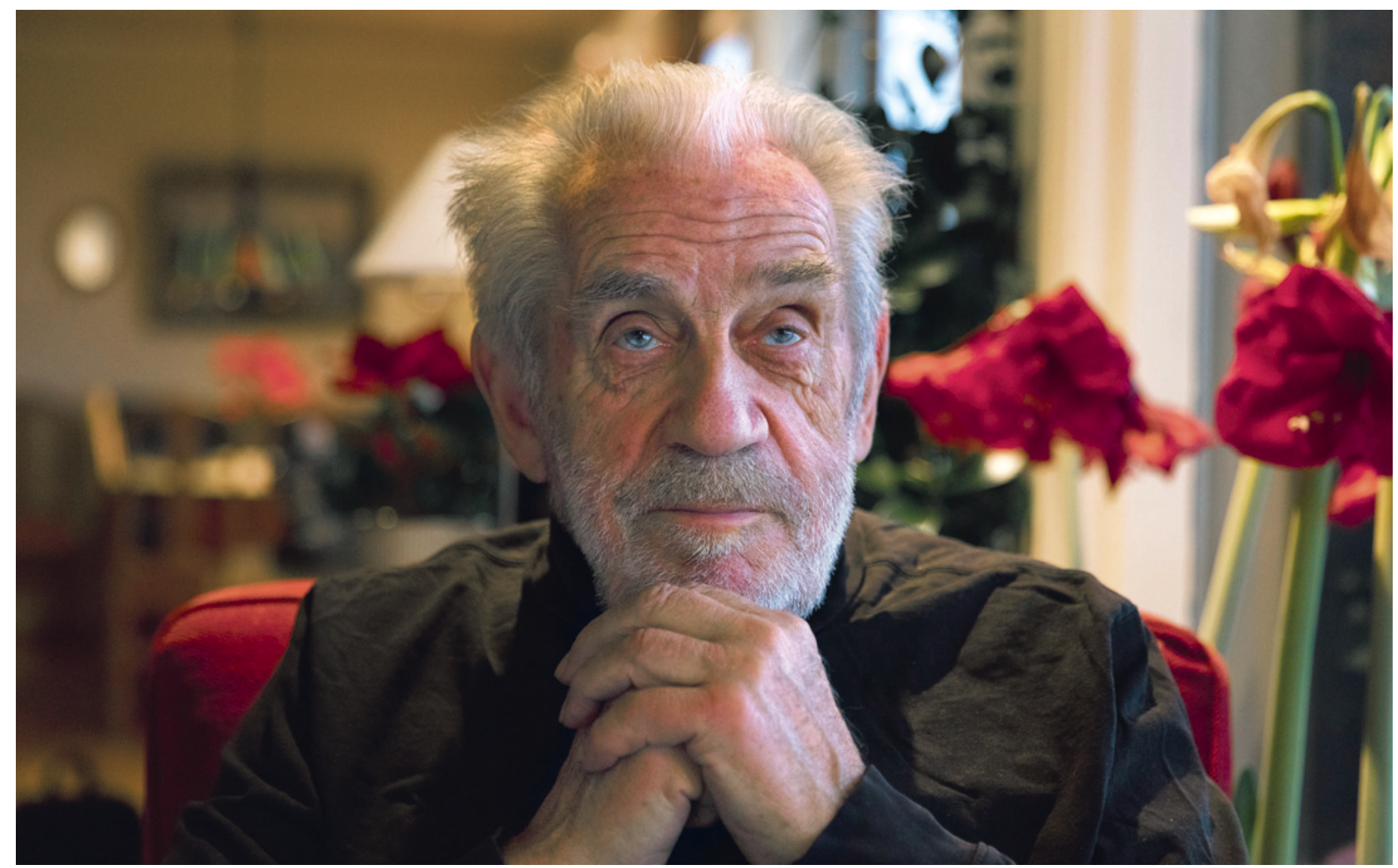

Foto: Christian Tunge

\section{Tore Midtvedt}

Født: 1934

- Cand.med. fra Universitetet i Bergen, 1958

- Har forelest i medisinsk mikrobiologi og i farmakologi (antibiotikal ved Universitetet i Oslo

- Dr.med. i medisinsk mikrobiell økologi ved Karolinska Institutet, 1968

- Professor og formann for avdeling for medisinsk mikrobiell økologi, celle- og molekylærbiologi ved Karolinska Institutet, 1983-99

- Tidligere president i International Association for Gnotobiology and Society for Medical Microbial Ecology

- Over 380 publikasjoner sitert i PubMed innenfor antibiotika, økologi, gnotobiologi, infeksjonsmedisin, mikrobiologi og farmakologi

- En av grunnleggerne av Anaerobic Cultivated Human Intestinal Microbiota (Achim) Biotherapeutics, 2013 hva ulike bakterier kunne gjøre med gallesyrer. Så ble jeg involvert i flere prosjekter, og etter hvert fikk jeg selv grønt lys på veldig mye.

- Så der var det gode vekstforhold for Tore Midtvedt?

- Ja, jeg hadde virkelig havnet midt i et smørøye. Det var jo flere nobelpristagere rundt meg, og alle var opptatt av mikrober. Det var akkurat da man hadde kartlagt biogene aminer som adrenalin og serotonin og kunne bestemme disse med moderne metoder. Gasskromatografen var nettopp oppfunnet på Karolinska - det bobla!, stråler Midtvedt.

\section{De autistiske rottene}

Den 82 år gamle legen er en viktig brikke $i$ et forskningsmiljø som $i$ årevis har engasjert seg i faglige diskusjoner om bakterier, antibiotika og kosthold. Han står bak hundrevis av publikasjoner og har gjort alt fra å skrive forordet til boken Takk for maten? av sosionom og homøopat Eva Fjeldstad til å holde hovedforelesningen på årsmøtet til American College of Nutrition i San Diego høsten 2016.

- Dere kobler altså mikrobiotiske faktorer til utvikling av en rekke sykdommer, som for eksempel diabetes, allergier, tarmsykdommer og autisme. Hva slags sammenhenger er det snakk om?

- Da må vi først snakke litt om epigenetikk. Et gen behøver ikke fungere på samme måte $\mathrm{i}$ forskjellige miljøer, det viser et enkelt forsøk jeg gjorde sammen med en amerikansk ph.d.-student. På Karolinska hadde vi både bakteriefrie og konvensjonelle rotter. Da dyrene var tre uker gamle produserte begge gruppene sukkermolekylet fukose, som det er mye av i tarmslim. Men da de var blitt tre måneder gamle, hadde de bakteriefrie dyrene slått av produksjonen. Så fikk jeg tak i en bakteriestamme som likte fukose og en som ikke likte det, og infiserte to grupper med bakteriefrie rotter. Dette gjorde vi på en fredag og allerede mandag var det bingo! De rottene som hadde blitt infisert med bakteriestammen som likte fukose hadde begynt å produsere det igjen. Altså måtte bakteriene kunne fortelle genene hos verten ting for å påvirke dem og si: «Hei! Nå er vi her!»

- Men hva har dette med for eksempel kostholdets effekt på autisme å gjøre?

- Det er ikke tvil om at tarmfloraen influerer på utvikling av autisme. Funksjonen påvirkes av mye mer enn genene bak, 
da snakker jeg om det miljømessige, også det mikrobielle. I tarmen vår produserer mikrobene for eksempel propionsyre. Flere konserveringsmidler, E-stoffer, inneholder også propionsyre. En hyperintelligent kanadier tok for noen år siden minimale mengder propionsyre og sprøytet inn i spinalvæsken på rotter, og så ble de autister! Rotten er jo normalt et sosialt, intelligent og nysgjerrig vesen, men disse rottene ble asosiale og fikk repetitiv atferd. Etter en halvtime var propionsyren borte fra spinalvæsken og rottene ble normale igjen. Det er derfor alle oppegående foreldre med autistiske barn nå baker sine brød selv. I butikken er alle brødene sprøytet med propionsyre for å hindre bakterievekst, forteller Midtvedt.

\section{Gode, gamle indolreaksjon}

Jeg ser noen YouTube-videoer fra det nevnte forsøket der kontrollrottene leker og klenger på hverandre, mens de propionsyreinjiserte vandrer apatisk for seg selv langs veggen av buret. Når kontrollrotten er alene snuser og titter den overalt, mens den andre bare spinner rundt og rundt seg selv. Det er vanskelig å tolke koblingen til autistiske mennesker og deres kosthold, men jeg er neppe den eneste som lar meg forvirre av tilpassede kostholdsråd.

- I dag eksisterer det et hav av ulike dietter som sies å ha effekter på alle mulige sykdomstilstander. Hvordan skal vanlige folk finne ut av denne jungelen?

- Jeg synes synd på lekfolk. Det er så mange predikanter der ute som prediker så mange forskjellige dietter. Det var grunnen til at vi på Karolinska i oktober 2016 konsentrerte oss om «The Food and the Mood». Ta for eksempel den essensielle aminosyren tryptofan, ingen dyr kan lage den, men planter og bakterier kan, og den er ufattelig viktig. Du har hatt mikrobiologi?

- Ja da, for et par år siden.

- Da vet du at det er noe som heter indolreaksjonen.

$-\mathrm{Njaa} .$.

- OK. Du bruker Ehrlichs reagens, paradimetylaminobenzaldehyd, for å vise at en mikrobe kan bryte ned tryptofan til et produkt som heter indol, som kan ha mange biologiske effekter. Tryptofanet selv kan være byggestein for eksempelvis serotonin og melatonin. Det inngår i mange sentrale hjernefunksjoner, understreker Midtvedt.

Paradimetylaminobenzaldehyd. Uten å blunke. Jeg kan høre den tynne isen slå sprekker mellom føttene mine, og vannet under er ikke grunt.

\section{Patent på ekskrement}

Jeg lister meg bortover isen, uten land i sikte, og konfronterer isbryteren foran meg med hans uttalelse til Dagens Næringsliv om at å gi probiotika til små barn er det største biologiske eksperimentet siden Hitlers. Matvareindustrien har nemlig lenge utviklet bakteriestammer, som LGG i blant annet Biola, til kommersiell utnyttelse.

- Probiotika er en gammel term, det er levende mikrober som kan være til nytte.

\section{«Jeg hadde en drøm om å bli proffsyklist og vinne Tour de France, jeg»}

Så har industrien fanget opp dette. Den første som kom med konseptet var egentlig Mechnikov, har du hørt om ham?

- Eh, nei ...

- Oi. Vel, han var et AD/HD-barn og et geni, disputerte som 16-åring og ... Her følger en detaljert mikrobiologisk-historisk utlegning som underbygger Midtvedts svar. Mechnikov, Ehrlich, Koch, Pasteur, noen sekker med geitemelk og en julefeiring ved Messina-stredet. Det er bare å kaste en livline mot land.

- Akkurat. Men jeg har hørt at du fortsatt jobber veldig mye, når legger du deg om kveldene egentlig?

- Når jeg har lyst! Men jeg starter ofte å jobbe i tretiden om natten, for da er det så få som ringer. Bare noen som vil Skype fra USA eller Canada i så fall. Men jeg oppfatter det ikke som jobb, jeg ser på det som interessant lek. Jeg føler meg privilegert som fortsatt kan være med og hjelpe til i miljøet.

I 2013 startet Midtvedt og fem andre forskere Achim Biotherapeutics. De er verdens første til å få patent på et økologisk system til behandling av antibiotikarelatert diaré ved hjelp av fecestransplantasjon. Transplantatet er en strengt utplukket og kjærlig bevoktet tarmflora fra en svært sjenerøs og svært anonym bergenser.

- Miljøet vårt har blitt oppfattet som «something completely different» av ledende eksperter, og det er en merkelapp jeg er veldig komfortabel med, sier han og kikker lurt over kaffekoppen.

\section{Å tenke sjæl}

Medisinen og mikrobene har vært en del av Tore Midtvedt i en mannsalder. Men da han var ung og vokste opp i Horten under krigen, var det selvberging som gjaldt.

- Far var egentlig i marinen, men etter 9. april etablerte han seg som småfisker i Skuggevika på Sørlandet. Det var utrolig tøffe forhold å skulle overleve i fem år av fiske fra en rosjekte, og jeg var med som mannskap fra jeg var syv år gammel. Jeg byttet annenhver dag mellom å gå på skole og hjelpe pappa, forklarer han.

Midtvedt fisker fortsatt nok om sommeren til at han og kona kan ha fisk flere ganger i uken gjennom hele året. Hytta på Brennevinsholmen mellom Arendal og Fevik er også et populært samlingssted for familien, der de årlig arrangerer Brandy Island Football Tournament.

Noe annet som har gitt ham mye glede er å undervise medisinstudenter. Selv har han vært utsatt for 48 forelesninger i uken pluss uketjeneste.

- Studentene hadde jo gått til Menneskerettighetsdomstolen for noe sånt $i$ dag. Jeg var sikkert en dårlig underviser selv da jeg begynte, for jeg ville lære dem detaljer. Etter hvert skjønte jeg betydningen av å lære dem prinsipper, så kan de heller få plassere detaljene selv. Men et uttrykk jeg ikke liker er «evidence based medicine». - Hvorfor ikke?

- Det sedimenterer gårsdagens oppfatninger. Jeg mener det prinsippet i stor grad er med på å begrense behandlingen av den enkelte pasient. Det er fremdeles så mange sykdommer og tilstander vi ikke vet nok om mekanismene til, og da må leger også kunne tenke og handle selvstendig, poengterer han.

Bakteriebeholderen fra 1934 bruker fortsatt ergometersykkelen i stuen, men det ble aldri noen Tour de France-seier på Tore Midtvedt. Han har likevel vært med på mange andre spennende og tunge etapper $i$ en medisinsk forskningsmaraton av de sjeldne.

- Fagfeltet ditt er jo ikke så stort, har du noen gang følt at du har jobbet litt i utkanten?

- Jeg er fullstendig oppmerksom på at jeg ikke har jobbet i noen utkant, men i forkant.

\section{Rune Skogheim}

runeskogheim@hotmail.com 